\title{
Antimicrobial and Phytochemical Screening of the Methanolic Stem Bark Extract of Ficus abutilifolia (Miq.) and Some Spectral Studies on One Isolated Component
}

\author{
Favour Danladi Makurvet $^{1 *} \quad$ George Iloegbulam Ndukwe ${ }^{2} \quad$ Emmanuel Uwaiya $^{2}$ \\ 1.Department of Chemistry, Kaduna State University, Tafawa Balewa Way, PMB 2339, Kaduna, Kaduna State, \\ Nigeria \\ 2.Department of Chemistry, Ahmadu Bello University, Sokoto Road, PMB 06, Zaria, Kaduna State, Nigeria
}

\begin{abstract}
The stem bark extract of Ficus abutilifolia (Miq.), an ethnomedicinally important member of the Moraceae family, was analysed with the three-fold aim of identifying its phytochemical components, determining its antimicrobial effects and efficacy, and isolating a component to be structurally elucidated by Fourier-Transform Infrared (FTIR) and Proton Nuclear Magnetic Resonance $\left({ }^{1} \mathrm{HNMR}\right)$ studies. Extraction was carried out by maceration method with methanol as the extraction solvent. Qualitative phytochemical analysis of the resulting methanolic extract gave positive results for carbohydrates, cardiac glycosides, saponins, steroid, triterpenes and alkaloids, while the antimicrobial screening revealed bioactivity against Staphylococcus aureus, Escherichia coli, and Pseudomonas aeruginosa. The extract was found to be bacteriostatic (growth-inhibitory) to $S$. aureus, E. coli and P. aeruginosa with respective Minimum Inhibitory Concentration (MIC) values of 25-, 50- and $25 \mathrm{mg} / \mathrm{ml}$, but was bactericidal (lethal) only to $S$. aureus and $P$. aeruginosa with a common Minimum Bactericidal Concentration (MBC) value of $50 \mathrm{mg} / \mathrm{ml}$. Column separation led to the successful isolation of a white crystalline substance with $\mathrm{R}_{\mathrm{f}}$ value of 0.25 using solvent ratio 1:4 of EtOAc:n-hexane solvent system. Studies on the FTIR and ${ }^{1}$ HNMR spectra of the isolated compound revealed that it is a non-aromatic, non-conjugated six-membered lactone.
\end{abstract}

Keywords: Ficus abutilifolia, antimicrobial screening, phytochemical, structural elucidation, isolation, stem bark, chromatography

DOI: $10.7176 / \mathrm{JNSR} / 10-6-05$

Publication date:March $31^{\text {st }} 2020$

\section{Introduction}

Medicinal plants constitute a promising source of pharmaceuticals but are far from being fully exploited. Plant antimicrobials must be relentlessly explored for treatment of diseases as they facilitate drug discovery and development and mitigate many of the side effects tenable with synthetic drugs. Globally, there are several hundred thousand medicinal plant species. However, only a relative few have undergone phytochemical and pharmacological investigations (Hostettmann, 1999).

Ficus abutilifolia (Miquel) belongs to the Moraceae family, which is often called the mulberry family or fig family. Moraceae is a family of flowering plants comprising about 40 genera and over 1,000 species, most of which are widespread in tropical and subtropical regions, less so in temperate climates. The largest genus in the mulberry family, Ficus is a genus of about 800 species of woody trees, shrubs and vines (Mahbubur and Anamika, 2013). Several species of this genus have been reported to exhibit both antimicrobial and pharmacological activities (Sandabe et al., 2003).

Commonly called large-leaved rock fig or rock wild fig and confined to rocky habitats, F. abutilifolia (Miq.) is found in bushveld savannah vegetation (Useful Tropical Plants, 2016) and widely distributed on the African continent (Taiwo et al., 2016). It is a small to medium sized, deciduous to semi-deciduous tree that may grow up to $15 \mathrm{~m}$ high (but seldom exceeds $5 \mathrm{~m}$ ). The plant has a yellowish-white, smooth and flaking bark and its trunk is usually twisted. Broadly ovate and cordate at base, the leaves usually measure 7.5-20.0 X 6.5-18.0 cm. The smooth or slightly hairy fruits are $1.5-2.5 \mathrm{~cm}$ in diameter usually borne singly or in pairs at the leaf axils (Danmallam et al., 2012).

According to Ukwubile (2010), glycosides such as saponins, flavonoids, anthraquinones as well as alkaloids and tannins mainly constitute the plant's phytochemical profile. Antibacterial activities of ethanol extract of its leaves against Salmonella typhi, Shigella dysenteriae and Staphylococcus aureus have also been reported (Ukwubile, 2010) and exploited traditionally by using the leaf extract to treat such ailments as typhoid fever, chronic dysentery, sexually transmitted infections, malaria and infertility particularly in South-eastern and Northern Nigeria (Taiwo et al., 2016). The milky latex is used to remove skin warts, bark decoction serves as a strengthening tonic for men and the root is used as part of a preparation for managing epilepsy (Burring, 2006).

In addition to the fact that there had been no published work on this plant part, the stem bark of F. abutilifolia seems to be known only for little ethnomedicinal application. Hence, it became pertinent to embark on this study in order to not only ascertain its potential as a traditional remedy and lead to drug discovery, but also isolate at 
least one of its components, followed by some structural analysis.

\section{Materials and Methods}

\subsection{Sample Collection and Preparation}

Ficus abitilifolia stem bark was collected from Tudun Wada of Kaduna North Local Government Area, Kaduna State, Nigeria, in September 2016, and authenticated taxonomically, with voucher number 900742, by Musa Abdullahi at the Herbarium, Department of Botany, Faculty of Science, Ahmadu Bello University, Zaria.

The stem bark was cut into smaller pieces, air-dried for four weeks (Pham et al., 2015) and pulverized using wooden pestle and mortar. The pulverized stem bark was preserved in an air-tight container to prevent contact with moisture.

\subsection{Preparation of Plant Extract}

Extraction was performed by maceration, in which $1000 \mathrm{~g}$ of the powdered Ficus abitulifolia stem bark was soaked in $4 \mathrm{~L}$ of methanol at room temperature for $72 \mathrm{~h}$. The extract was then filtered using Whatman filter paper no. 2 and concentrated in vacuo at $40{ }^{\circ} \mathrm{C}$ on a rotary evaporator to dryness.

\subsection{Preliminary Phytochemical Analysis of Plant Extract}

The plant extract was screened for the presence of carbohydrates, cardiac glycosides, saponins, steroid and triterpenes, flavonoids, tannins, alkaloids, and anthraquinones, according to established procedures (Trease and Evans, 1989; Sofowora, 1993).

\subsubsection{Test for Carbohydrates (Molisch's Test)}

About $1.0 \mathrm{~g}$ of the plant extract was dissolved in distilled water and filtered. Few drops of Molisch's reagent and concentrated $\mathrm{H}_{2} \mathrm{SO}_{4}$ were added. Appearance of a red colouration at the interface of two layers was taken to indicate the presence of carbohydrates.

2.3.2 Test for Cardiac Glycosides (Keller-Killani Test)

About $1.0 \mathrm{~g}$ of the plant extract was dissolved in pyridine and few drops of $2 \%$ sodium nitroprusside solution with few drops $2 \% \mathrm{NaOH}$ solution were added. Appearance of a deep red colouration which faded to brownish yellow was taken to indicate the presence of cardiac glycosides.

\subsubsection{Test for Saponins (Froth Test)}

Freshly prepared $7 \%$ blood agar medium was used, and wells were made in it. The extract in methanol was applied with distilled water and methanol was used as negative control while commercial saponin (BDH) solution was used as positive control. The plates were incubated at $35^{\circ} \mathrm{C}$ for $6 \mathrm{~h}$. Complete haemolysis of the blood around the extract was taken to indicate the presence of saponins.

\subsubsection{Test for Steroid and Triterpenes (Lieberman-Buchard's Test)}

About $2 \mathrm{mg}$ of the plant extract was dissolved in acetic anhydride, heated to boiling, cooled and then $1 \mathrm{ml}$ of concentrated sulphuric acid was added along the sides of the test tube. Appearance of a pink colouration was taken to indicate the presence of steroid and triterpenes.

\subsubsection{Test for Flavonoids (Hydrochloric Acid Test)}

About $0.2 \mathrm{~g}$ of the extract was dissolved in $2 \mathrm{ml}$ of methanol and heated. A chip of magnesium metal was added to the mixture followed by the addition of a few drops of concentrated hydrochloric acid. The occurrence of a red or orange colouration was taken to indicate the presence of flavonoids.

2.3.6 Test for Tannins (Ferric Chloride Test)

About $1 \mathrm{~g}$ of the extract was dissolved in $20 \mathrm{ml}$ of distilled water and filtered, and 2 to 3 drops of $10 \%$ of $\mathrm{FeCl}_{3}$ was added to $2 \mathrm{ml}$ of the filtrate. The production of a blackish-blue or blackish-green colouration was indicative of the presence of tannins. To another $2 \mathrm{ml}$ of the filtrate was added $1 \mathrm{ml}$ of bromine water. Precipitation was taken to be confirmative of the presence of tannins.

\subsubsection{Test for Alkaloids (Meyer's Test)}

Exactly $0.5 \mathrm{~g}$ of the plant extract was dissolved in $5 \mathrm{ml}$ of $1 \% \mathrm{HCl}$ on steam bath, after which exactly $1 \mathrm{ml}$ of the filtrate was treated with drops of Dragendorff's reagent. Turbidity was taken to indicate the presence of alkaloids. 2.3.8 Test for Anthraquinones (Borntrager's Test)

About $1.0 \mathrm{~g}$ of the plant extract was dissolved in petroleum ether and filtered. Aqueous ammonia was then added to the filtrate. Appearance of a pink colouration was taken as an indication of the presence of anthraquinones in the plant extract.

\subsection{Phytochemical Isolation}

An attempt was made to isolate one or more phytochemical components present in the plant extract using Column Chromatography (CC), which was preceded using Thin Layer Chromatography (TLC) to determine the solvent system to be employed for the column separation. The solvent system used was n-hexane:ethylacetate. 


\subsubsection{TLC Procedure for Determination of Solvent System to be employed}

A line was drawn about $0.5 \mathrm{~cm}$ from the bottom of the TLC plate using a pencil. Points were indicated along the line for each spot.

A thin capillary tube was dipped into the methanolic solution of the extract and a 1-2 $\mathrm{mm}$ spot was quickly placed on the plate at the marked positions. Approximately $3 \mathrm{ml}$ of the development solvent was transferred into a screwcapped jar containing a piece of solvent-wet filter paper. The solvent was shallow enough to be below the spot line on the plate. The plate was carefully placed in the chamber using tongs and the jar was capped to allow the plate to develop.

When the solvent front had almost reached the top of the TLC plate, the plate was removed and the solvent front was immediately marked with a pencil line. The plate was visualised under ultraviolet (uv) lamp and the observed spots that were initially unseen were outlined with a pencil. Where necessary, the plate was charred by spraying with $10 \%$ tetraoxosulphate (VI) acid $\left(\mathrm{H}_{2} \mathrm{SO}_{4}\right)$ and heating in an oven, and the outline was further marked ' $\mathrm{x}$ '. In each case, the respective $\mathrm{R}_{\mathrm{f}}$ values were duly computed and recorded.

\subsubsection{Chromatographic Separation of the Phytoconstituents in the Plant Extract}

Column specifications used were length of $100 \mathrm{~cm}$ and diameter of $3.5 \mathrm{~mm}$. The stationary phase used was silica gel, which was first activated at $110^{\circ} \mathrm{C}$ for $1 \mathrm{~h}$. The column separation was carried out with solvent ratios of 1:9, $1: 4,3: 7,2: 3$ and $1: 1$ in this order for ethylacetate:n-hexane, and then in the reverse order for n-hexane:ethylacetate. Slurry method was employed for column packing and dry loading was used for sample introduction.

Approximately $60 \mathrm{~g}$ of the activated silica gel and $2 \mathrm{~g}$ of the plant extract were weighed. The $2 \mathrm{~g}$ of extract was dissolved in absolute minimum amount of methanol, after which enough of the silica gel was added and mixed for dry loading. The resulting solid was allowed to dry completely.

A small wad of cotton wool was placed at the bottom of the column, which was then clamped to a retort stand. A small piece of filter paper was cut out in circular shape and placed at the bottom on top of the cotton wool. The solvent n-hexane was poured into the column up to the $50-\mathrm{cm}$ mark and the column was tapped repeatedly and lightly to expel air bubbles, with the tap left open for continuous elution of the mobile phase.

Slurry of silica gel was prepared by transferring some quantity of the pre-weighed gel into a beaker and adding enough n-hexane. The slurry was then transferred at once, through a filter funnel, into the solvent-containing column. More slurry was added until the stationary phase was built up to the $25-\mathrm{cm}$ mark of the column. Solvent was being added into the open-tap column which was frequently tapped with the finger to expel air bubbles, and the eluent was returned into the column each time. The length of the stationary phase was further increased by addition of more slurry into the column until the pre-weighed silica gel was exhausted. The solvent level was always maintained above the stationary phase.

A second small wad of cotton wool was placed on the surface of the stationary phase, after which the drypacked extract was gently introduced into the column. A third small wad of cotton wool was placed on the surface of the extract in the column. As always, the solvent level was maintained above the entire content of the column by addition of more solvent into the column.

Fractions of eluent were collected in labeled test tubes and TLC was carried out intermittently to monitor the column separation. Test tubes with the same TLC result were considered to contain the same component(s) and their contents were combined and evaporated to dryness, leaving behind the isolated component.

\subsection{Spectroscopic Determinations of the Isolated Component}

Spectroscopic analysis was carried out on the isolated component to obtain its FTIR and ${ }^{1} \mathrm{HNMR}$ spectra.

\subsection{Antimicrobial Assays}

Pure clinical isolates of Staphylococcus aureus, Bacillus subtilis, Escherichia coli, Salmonella typhi, Pseudomonas aeruginosa, and Klebsiella pneumoniae, collected from the Department of Microbiology, Ahmadu Bello University, Zaria, were used for the experiment.

The culture media used for the antimicrobial screening included Mueller Hinton Agar (MHA) for sensitivity test, Mueller Hinton Broth (MHB) for determination of MIC, and Nutrient Agar (NA) for determination of MBC. All media were prepared according to manufacturer's instructions and sterilised by autoclaving at $121{ }^{\circ} \mathrm{C}$ for 15 minutes.

\subsubsection{Determination of Inhibitory Activity (Sensitivity Test) of the Plant Extract}

Sensitivity test of the plant extract was carried out using Agar Well Diffusion method (Norrel and Messley, 1997). The standardised inocula of the bacterial isolates were streaked on sterilised MHA plates with the aid of a sterile swab stick. Four wells were punched on each inoculated agar plate with a sterile cork borer. The wells were properly labeled according to the different concentrations of the extract prepared, namely 100-, 50-, 25- and 12.5 $\mathrm{mg} / \mathrm{ml}$. Each well was filled up with approximately $0.2 \mathrm{ml}$ of the extract. The inoculated plates with the extract were allowed to stay on the bench for about $1 \mathrm{~h}$ so as to enable the extract to diffuse into the agar. The plates were then incubated at $37^{\circ} \mathrm{C}$ for $24 \mathrm{~h}$. 
At the end of the incubation period, the plates were observed for any evidence of inhibition, which appeared as a clear zone that was completely devoid of microbial growth around the wells (zone of inhibition). The diameters of the zones were measured using a transparent ruler calibrated in millimeter, and the results were duly recorded.

2.6.2 Determination of MICs of the Plant Extract

The MIC of the extract against each test organism was determined using the Tube Dilution method with the Mueller Hinton Broth used as a diluent (Chitwood, 1969). The lowest concentration of the extract that showed inhibition for each organism during the sensitivity test was serially diluted in test tubes containing MHB. The test organisms were inoculated into each tube containing the broth and the extract. The inoculated tubes were then incubated at $37^{\circ} \mathrm{C}$ for $24 \mathrm{~h}$.

At the end of the incubation period, the tubes were carefully examined for the presence of microbial growth, using turbidity as a criterion. The lowest concentration in the series without visible sign of growth (turbidity) was the MIC and was duly recorded.

2.6.3 Determination of $M B C s$ of the Plant Extract

The results from the MIC test were used to determine the MBCs of the plant extract.

A sterilised wire loop was dipped, one at a time, into the test tubes that did not show turbidity in the MIC test, and a loopful was taken and streaked on sterile nutrient agar plates. The plates were incubated at $37{ }^{\circ} \mathrm{C}$ for $24 \mathrm{~h}$.

At the end of the incubation period, the plates were carefully examined for the presence of microbial growth. The lowest concentration that showed complete absence of microbial growth was taken to be the MBC and was duly recorded.

\section{Results and Discussion}

3.1 Results of Phytochemical Analysis

Table 1. Results for Qualitative Phytochemical Analysis of the Methanolic Stem Bark Extract of F. abutilifolia (Miq.)

\begin{tabular}{|c|l|l|c|}
\hline S/N & \multicolumn{1}{|c|}{ Test } & \multicolumn{1}{c|}{ Phytochemical } & Result \\
\hline 1 & Molisch's & Carbohydrates & + \\
\hline 2 & Kelle-Killani's & Cardiac glycosides & + \\
\hline 3 & Froth's & Saponins & + \\
\hline 4 & Lieberman-Buchard's & Steroid and Triterpenes & + \\
\hline 5 & Hydrochloric Acid & Flavonoids & - \\
\hline 6 & Ferric Chloride & Tannins & - \\
\hline 7 & Meyer's & Alkaloids & + \\
\hline 8 & Borntrager's & Anthraquinones & - \\
\hline
\end{tabular}

Key: + = Present; - = Absent

\subsection{Results of Phytochemical Isolation}

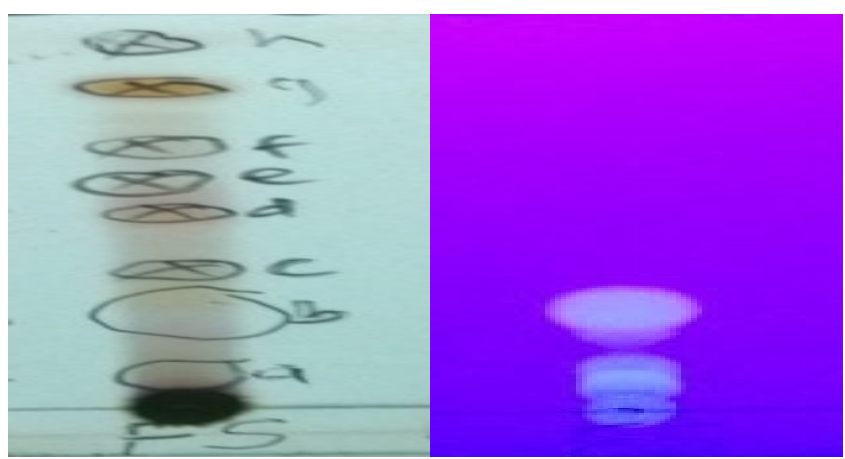

(i)

(ii)

Figure 1. TLC Images for the Separated Components as observed (i) without UV and (ii) with UV light 


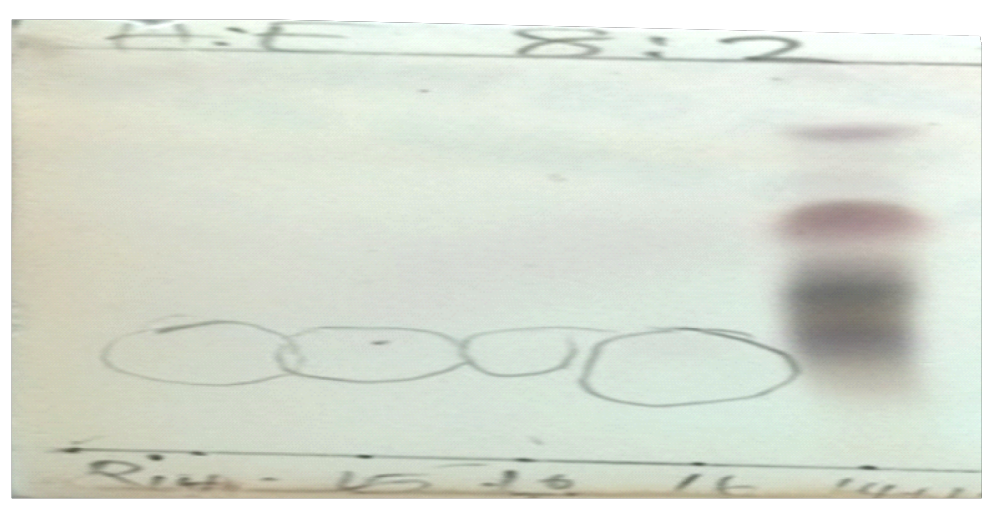

Figure 2. TLC Image of the Isolated Component

Table 2. TLC Results for Components Partitioned with Solvent Ratio 1:4 of ethylacetate:n-hexane

\begin{tabular}{|c|c|c|c|c|}
\hline $\mathbf{S} / \mathbf{N}$ & Component & $\mathbf{X}(\mathbf{c m})$ & $\mathbf{Y}(\mathbf{c m})$ & $\mathbf{R}_{\mathbf{f}}=\mathbf{X} / \mathbf{Y}$ \\
\hline 1 & $\mathrm{a}$ & 0.4 & 4.2 & 0.10 \\
\hline 2 & $\mathrm{~b}$ & 0.9 & 4.2 & 0.21 \\
\hline 3 & $\mathrm{c}$ & 1.4 & 4.2 & 0.33 \\
\hline 4 & $\mathrm{~d}$ & 2.1 & 4.2 & 0.50 \\
\hline 5 & $\mathrm{e}$ & 2.4 & 4.2 & 0.57 \\
\hline 6 & $\mathrm{f}$ & 2.8 & 4.2 & 0.67 \\
\hline 7 & $\mathrm{~g}$ & 3.4 & 4.2 & 0.81 \\
\hline 8 & $\mathrm{~h}$ & 3.8 & 4.2 & 0.90 \\
\hline
\end{tabular}

$\mathrm{X}=$ Distance moved by component; $\mathrm{Y}=$ Distance moved by solvent front

The chromatographic separation process resulted in the successful isolation of a compound with the solvent ratio 1:4 of ethylacetate:n-hexane. The isolated component was white and crystalline, with a retention factor $\left(\mathrm{R}_{\mathrm{f}}\right)$ value of 0.25 given that $X=1 \mathrm{~cm}$ and $\mathrm{Y}=4 \mathrm{~cm}$.

\subsection{Results of Antimicrobial Screening}

Table 3a. Results for Sensitivity Test on the Methanolic Stem Bark Extract of F. abutilifolia (Miq.)

\begin{tabular}{|c|l|c|}
\hline S/N & \multicolumn{1}{|c|}{ Test Organism } & Inhibitory Activity \\
\hline 1 & Staphylococcus aureus & + \\
\hline 2 & Bacillus subtilis & - \\
\hline 3 & Escherichia coli & + \\
\hline 4 & Salmonella typhi & - \\
\hline 5 & Pseudomonas aeruginosa & + \\
\hline 6 & Klebsiella pneumonia & - \\
\hline
\end{tabular}

Key: + = Present; - = Absent

Table 3b. Diameters of Inhibition Zones at Different Concentrations of the Methanolic Stem Bark Extract of $F$. abutilifolia (Miq.)

\begin{tabular}{|c|c|c|c|c|c|c|}
\hline \multirow[t]{3}{*}{$\mathbf{S} / \mathbf{N}$} & \multirow[t]{3}{*}{ Test Organism } & \multicolumn{5}{|c|}{$\begin{array}{l}\text { Diameters of Inhibition Zones (mm) } \\
\text { by }\end{array}$} \\
\hline & & \multicolumn{4}{|c|}{$\begin{array}{l}\text { Plant Extract at Concentration } \\
(\mathrm{mg} / \mathrm{ml}) \\
\text { of }\end{array}$} & \multirow[t]{2}{*}{$\begin{array}{c}\text { Ciprofloxacin (Standard } \\
\text { Antibiotic) }\end{array}$} \\
\hline & & 100 & 50 & 25 & 12.5 & \\
\hline 1 & Staphylococcus aureus & 16 & 14 & 12 & 0 & 35 \\
\hline 2 & Bacillus subtilis & 0 & 0 & 0 & 0 & 42 \\
\hline 3 & Escherichia coli & 17 & 15 & 12 & 0 & 40 \\
\hline 4 & Salmonella typhi & 0 & 0 & 0 & 0 & 36 \\
\hline 5 & $\begin{array}{l}\text { Pseudomonas } \\
\text { aeruginosa }\end{array}$ & 18 & 16 & 14 & 0 & 36 \\
\hline 6 & Klebsiella pneumonia & 0 & 0 & 0 & 0 & 37 \\
\hline
\end{tabular}


Table 4. MICs of the Methanolic Stem Bark Extract of F. abutilifolia (Miq.) against the Inhibited Test Organisms

\begin{tabular}{|c|l|c|c|c|c|}
\hline \multirow{2}{*}{ S/N } & \multirow{2}{*}{ Test Organism } & \multicolumn{4}{|c|}{ Concentrations (mg/ml) } \\
\cline { 3 - 6 } & & 100 & 50 & 25 & 12.5 \\
\hline 1 & Staphylococcus aureus & -- & -- & $*_{--}$ & ++ \\
\hline 2 & Escherichia coli & -- & $*_{--}$ & ++ & ++ \\
\hline 3 & Pseudomonas aeruginosa & -- & -- & $*_{--}$ & ++ \\
\hline
\end{tabular}

$$
\text { Key: ++ = Growth; -- = No Growth; *-- = MIC }
$$

Table 5. MBCs of the Methanolic Stem Bark Extract of F. abutilifolia (Miq.) against the Inhibited Test

\begin{tabular}{|c|l|c|c|c|c|}
\multicolumn{7}{c|}{ Organisms } \\
\cline { 3 - 6 } S/N & \multicolumn{1}{|c|}{ Test Organism } & \multicolumn{5}{c|}{ Concentrations (mg/ml) } \\
\hline 1 & Staphylococcus aureus & - & ${ }^{*}-$ & + & + \\
\hline 2 & Escherichia coli & + & + & + & + \\
\hline 3 & Pseudomonas aeruginosa & - & ${ }^{*}-$ & + & + \\
\hline
\end{tabular}

Key: + = Present; - = Absent; *- = MBC

Table 6. Summary of Test Results for MIC and MBC of the Methanolic Stem Bark Extract of F. abutilifolia (Miq.) against the Inhibited Test Organisms

\begin{tabular}{|c|l|c|c|}
\hline S/N & \multicolumn{1}{|c|}{ Test Organism } & MIC (mg/ml) & MBC (mg/ml) \\
\hline 1 & Staphylococcus aureus & 25 & 50 \\
\hline 2 & Escherichia coli & 50 & $\mathrm{X}$ \\
\hline 3 & Pseudomonas aeruginosa & 25 & 50 \\
\hline
\end{tabular}

$$
\text { Key: } \mathrm{x}=\text { No MBC }
$$

\subsection{Spectral Results}

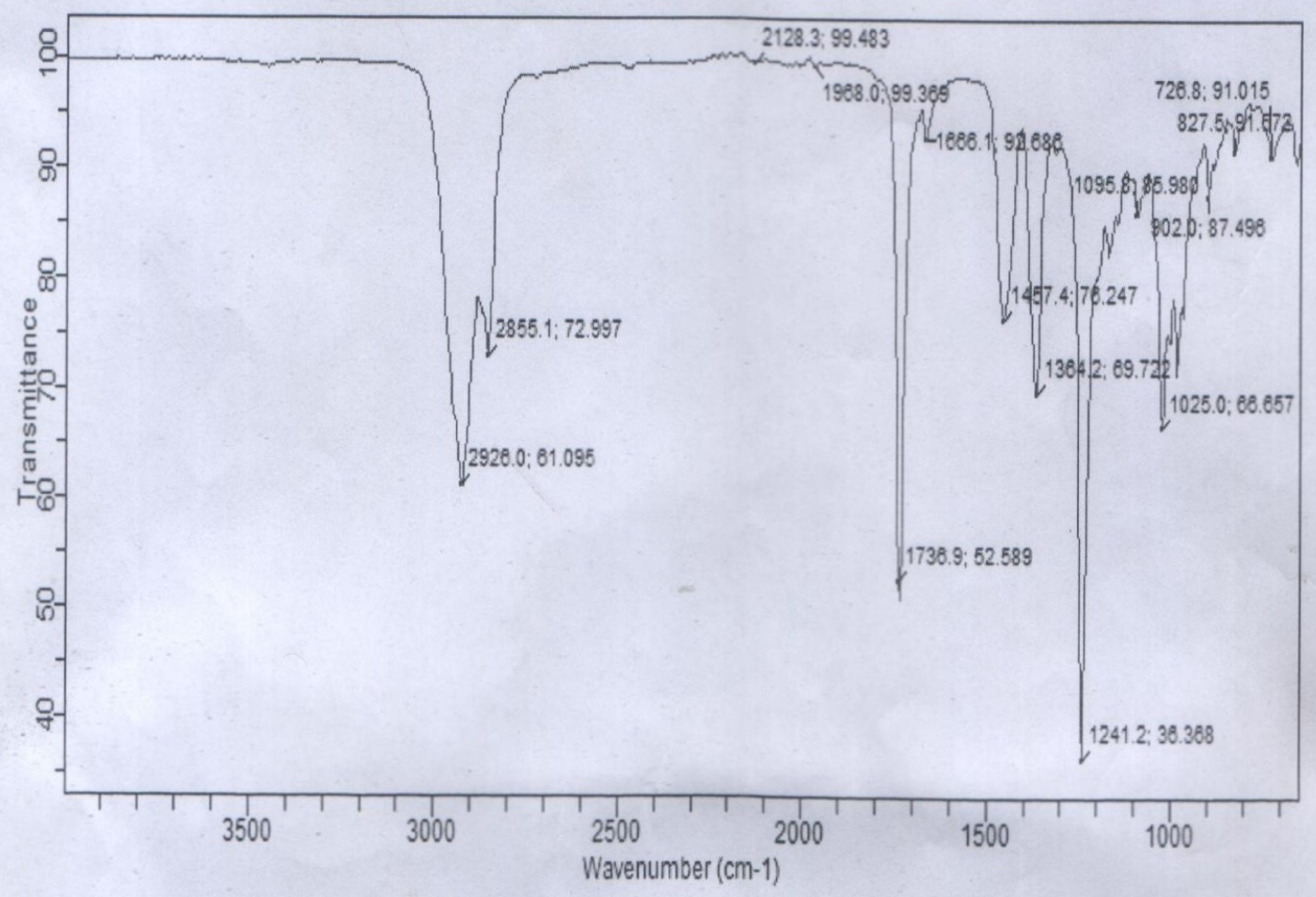

Figure 3. FTIR Spectrum of the Isolated Component 


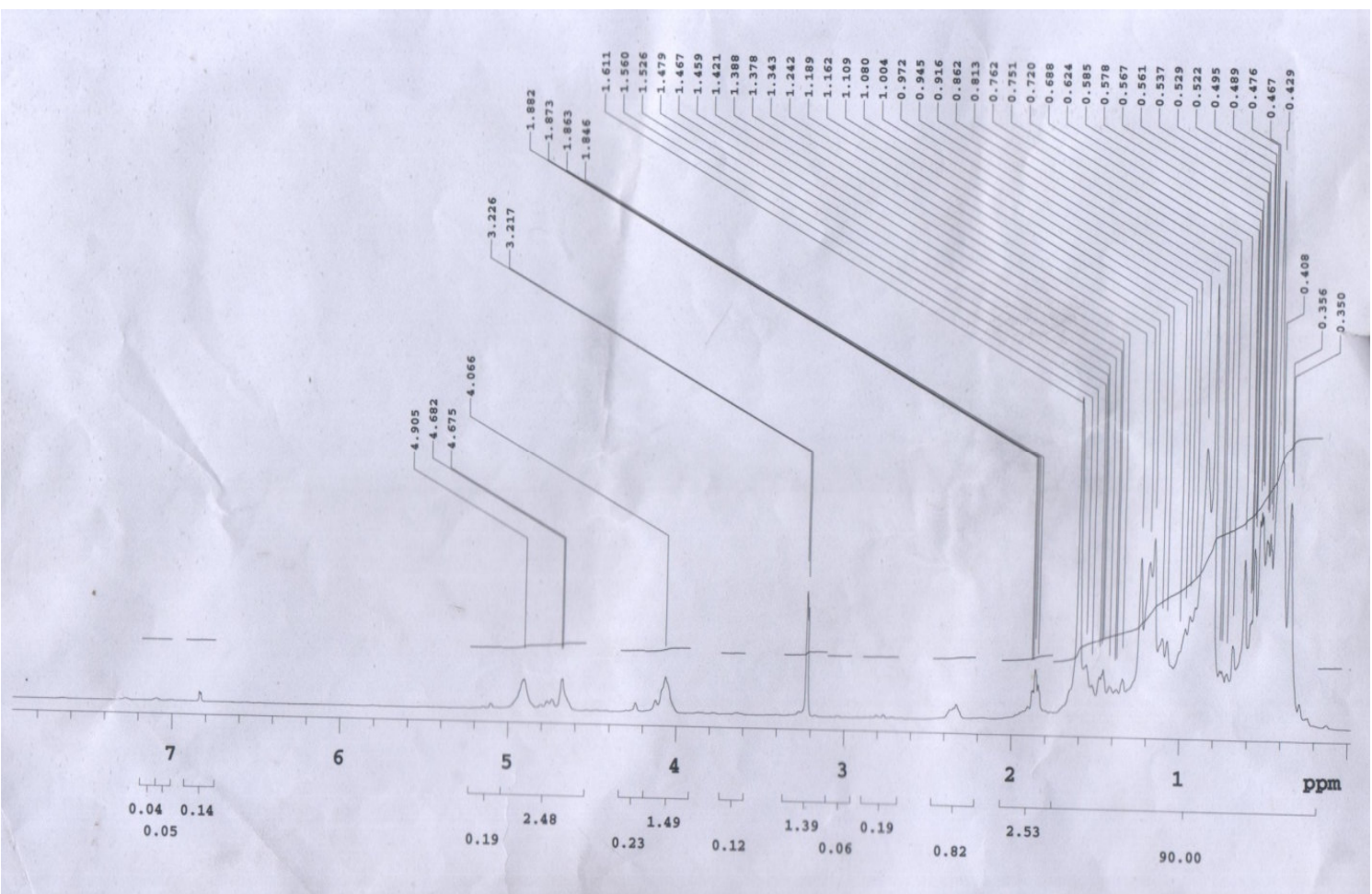

Figure 4. ${ }^{1}$ HNMR Spectrum of the Isolated Component

The phytochemical screening of the methanolic stem bark extract of $F$. abutilifolia (Miq.) revealed the presence of carbohydrates, cardiac glycosides, saponins, steroid and triterpenes, and alkaloids (Table 1). The secondary metabolites are responsible for the various biological activities observed in the antimicrobial screening of the extract.

The chromatographic separation revealed that component ' $b$ ', as seen from the TLC result (Figure 2 and Table 2 ), was successfully isolated. This is supported by the fact that component ' $b$ ' had a $R_{f}$ value of 0.21 , which is the closest to 0.25 , the $\mathrm{R}_{\mathrm{f}}$ value of the isolated component.

From the antimicrobial screening results, it was evident that the extract was bioactive against Staphylococcus aureus, Escherichia coli, and Pseudomonas aeruginosa (Tables 3a and 3b) and the MIC test results (Table 4) support this fact. In addition, the MIC test results revealed that the extract was more bacteriostatic to S. aureus and $P$. aeruginosa, whose growths were inhibited at a common MIC of $25 \mathrm{mg} / \mathrm{ml}$ of extract. The growth of $E$. coli was relatively less inhibited by the extract since growth inhibition required twice the MIC against the former test organisms (Table 4). The MBC test results showed that the extract was bactericidal to only $S$. aureus and $P$. aeruginosa with a common MBC of $50 \mathrm{mg} / \mathrm{ml}$ (Table 5), which is twice their MIC (Table 6).

From the FTIR spectrum of the isolated component (Figure 3), $\mathrm{sp}^{3} \mathrm{C}-\mathrm{H}_{\text {stretch }}$ was detected at $2926.0 \mathrm{~cm}^{-1}$ and $2855.1 \mathrm{~cm}^{-1}$. $\mathrm{C}=\mathrm{O}$ functional group was found to be present at $1736.9 \mathrm{~cm}^{-1}$. Also, the narrow weak absorption band at $1666.1 \mathrm{~cm}^{-1}$ was due to $\mathrm{C}=\mathrm{C}_{\text {stretch, }}$, indicating olefinic unsaturation. This is supported by the single band at 902.0

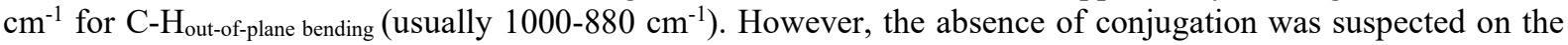
basis that the detected $\mathrm{C}=\mathrm{C}_{\text {stretch }}$ was not less than $1650 \mathrm{~cm}^{-1}$ and the corresponding band was not intense but narrow and weak (John, 2000). The peaks at $1241.2 \mathrm{~cm}^{-1}$ and $1025 \mathrm{~cm}^{-1}$ are due to C-O $\mathrm{O}_{\text {stretch }}$ for ester since they correspond to $1250 \mathrm{~cm}^{-1}$ and $1050 \mathrm{~cm}^{-1}$, respectively. The detected $\mathrm{C}=\mathrm{O}_{\text {stretch }}$ at $1736.9 \mathrm{~cm}^{-1}$ lies within the range of $1750-1735$ $\mathrm{cm}^{-1}$ (Ashenhurst, 2020), suggesting that the carbonyl group of the isolated compound is that of a six-membered lactone (Merck, 2020), which is a cyclic ester.

The ${ }^{1}$ HNMR spectrum (Figure 4) indicated the presence of different hydrogen environments shown by the chemical shift values below:

- $\quad 0.916-0.945 \mathrm{ppm}$ for $\mathrm{RCH}_{3}$

- $\quad 1.242-1.421 \mathrm{ppm}$ for $\mathrm{RCH}_{2} \mathrm{R}$

- $\quad 1.420$ - $1.611 \mathrm{ppm}$ for $\mathrm{R}_{3} \mathrm{CH}$

- $\quad 3.217-3.226 \mathrm{ppm}$ for $\mathrm{RCH}_{2} \mathrm{I}$

- $\quad 4.066-4.682 \mathrm{ppm}$ for $\mathrm{RCOOCH} \mathrm{H}_{2} \mathrm{R}$

- $\quad 4.675$ - $4.905 \mathrm{ppm}$ for $\mathrm{R}_{2} \mathrm{C}=\mathrm{CR}-\mathrm{CHR} \mathrm{R}_{2}$

These values suggest that the corresponding chemical components or functionalities were present, the most important being the ester-indicating chemical shift of $4.066-4.682 \mathrm{ppm}$. The isolated compound is not aromatic as indicated by the absence of peaks in the aromatic region, which typically lies in the 6.5-8.5 ppm range (Jacobsen, 
2016). The ratio of integration numbers (from left to right of Figure 4) was found to be 2.48:1.49:1.39:2.53:90, approximately given as 2:1:1:3:90. This integral ratio can be helpful in ascertaining the actual number of hydrogen atoms in each environment. It can also be inferred that there are at least five different $\mathrm{H}$-containing environments.

Although only two spectroscopic techniques were employed towards the structural elucidation of the isolated compound, the ${ }^{1} \mathrm{HNMR}$ result was significantly consistent with the FTIR result in as much as the presence of a cyclic ester with olefinic unsaturation was concerned.

\section{Conclusion}

The stem bark of F. abutilifolia (Miq.) contains carbohydrates, cardiac glycosides, saponins, steroid and triterpenes, and alkaloids. The phytoconstituents of this morphological plant part are both bacteriostatic and bactericidal to Staphylococcus aureus and Pseudomonas aeruginosa, giving credence to the traditional application of this plant part for treatment of skin warts and dermatitis (Danmallam et al., 2012).

Therefore, phytodrugs from $F$. abutilifolia (Miq.) may serve as potential precursors for the preparation of certain Active Pharmaceutical Ingredients (APIs). This plant can be a source of modern therapeutic formulations for potential drugs to be used in orthodox medicine for the treatment of diseases caused by $S$. aureus and $P$. aeruginosa.

Though full structural elucidation was not carried out, a non-conjugated six-membered lactone devoid of aromaticity was successfully isolated. However, further work on F. abutilifolia (Miq.) is necessary to know the biological activities of different other extracts of the stem bark and compare with those of the methanolic extract. Also, advanced studies such as pharmacognostic studies and complete structural elucidation of the isolated component should be carried out to know the full potential of this plant as a source of on-the-counter drugs. Tradomedicine would always provide steppingstones to greater heights in modern medicine.

\section{Acknowledgement}

Our immense gratitude goes to the Department of Chemistry, Kaduna State University, and the Departments of Chemistry, Botany and Microbiology, Ahmadu Bello University, for providing the space, materials and instrumentation requisite to the success of this research work.

\section{Conflict of Interest}

The authors declare no competing financial interest.

\section{References}

Ashenhurst

J. (2020)

Spectroscopy.

Retrieved

from: https://www.masterorganicchemistry.com/2016/11/23/quick_analysis_of_ir_spectra/ [Accessed January, 2020].

Burring, J. (2006). Ficus abutilifolia. Retrieved from: http:/www.plantzafrica.com/plantefg/ficusabuti.htm [Accessed October 2016].

Chitwood, L. A. (1969). Tube dilution antimicrobial susceptibility testing: Efficacy of a microtechnique applicable to diagnostic laboratories. Appli. Microbiology, 17(5): 707-709. Retrieved from: https://aem.asm.org/content/aem/17/5/707.full.pdf.

Danmalam, U. H., Allahmagani, P. K., Ilyas, N., Abdurahman, E. M., Yaro, A. H. and Magaji, M. G. (2012). Phytochemical and anticonvulsant studies on the aqueous ethanol extract of the root-back of Ficus abutilifolia (Miq.) Miq. (Family: Moraceae). Journal of Applied Pharmaceutical Science, 2(7): 234-237. DOI: 10.7324/JAPS.2012.2739.

Hostettmann, K. (1999). Strategy for the biological and chemical evaluation of plant extracts. Pure Appl. Chem., 70(11): 1-9. Retrieved from: http://www.iupac.org/symposia/proceedings/phuket97/hostettmann.html.

Jacobsen, N. E. (2016). NMR data interpretation explained: Understanding $1 D$ and 2D NMR spectra of organic compounds and natural products. Hoboken, New Jersey: John Wiley and Sons, Inc.

John, C. (2000). Interpretation of infrared spectra, a practical approach. In: Meyers, R. A. (ed.), Encyclopedia of Analytical Chemistry. Chichester: John Wiley \& Sons Ltd, pp. 10815-10837.

Mahbubur, R. and Anamika, K. (2013). A taxonomic and ethnomedicinal study of species from Moraceae (mulberry) family in Bangladesh flora. Research in Plant Sciences, 1(3): 53-57. DOI: 10.12691/plant-1-3-1.

Merck (2020). IR spectrum table and chart. Retrieved from: https://www.sigmaaldrich.com/technicaldocuments/articles/biology/ir-spectrum-table.html [Accessed January 2020].

Norrel, S. A. and Messley, K. E. (1997). Microbiology Laboratory Manual Principles and Applications. Upper Saddle River, New Jersey: Prentice Hall.

Pham, H. N. T., Nguyen, V. T., Vuong, Q. V., Bowyer, M. C. and Scarlett, C. J. (2015). Effect of extraction solvents and drying methods on the physicochemical and antioxidant properties of Helicteres hirsuta Lour. leaves. Technologies, 3: 285-301. DOI: 10.3390/technologies3040285. 
Sandabe, U. K., Onyelili, P. A. and Chibuzo, G. A. (2003). Sedative and anticonvulsant effects of aqueous extract of Ficus sycomorus L. (Moraceae) stem bark in rats. Veterinarski Arhiv., 73(2):103-110. Retrieved from: https://pdfs.semanticscholar.org/bdc0/becdc132b06d8710cf80fda7b9fb10b63689.pdf.

Sofowora, A. E. (1993). Medicinal Plants and traditional medicines in Africa (2nd ed.). Ibadan: Spectrum Books.

Taiwo, F. O., Fidelis, A. A. and Oyedeji, O. (2016). Antibacterial activity and phytochemical profile of leaf extracts of Ficus abutilifolia. British Journal of Pharmaceutical Research, 11(6): 1-10. DOI: 10.9734/BJPR/2016/25608.

Trease, G. E. and Evans, W. C. (1989). Pharmacognosy (13th ed.). London: ELBS/Bailliere Tindall.

Ukwubile, C. A. (2010). Pharmacognostic, Antibacterial and Toxicity Investigations of Ficus abutlilifolia Miq. (Moraceae). International Journal of Biological Sciences, 2(8): 98-111. Retrieved from: http://www.ijapbc.com/files/14-2119.pdf. Useful Tropical
Plants
(2016).
Ecocrop.
Retrieved
from: http://www.tropical.theferns.info/viewtropical.php?id=Ficus+abutilifolia [Accessed October 2016]. 